\title{
Introducing a Second Ligand: New Route to Luminescent Lanthanide Polyphosphonates
}

\author{
Shao-Ming Ying ${ }^{[a]}$ and Jiang-Gao Mao ${ }^{*[a]}$
}

Supporting Materials

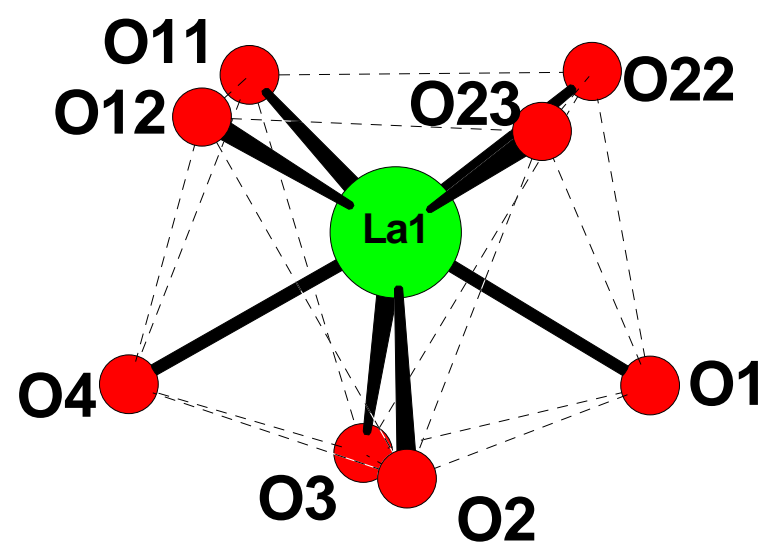

(a)

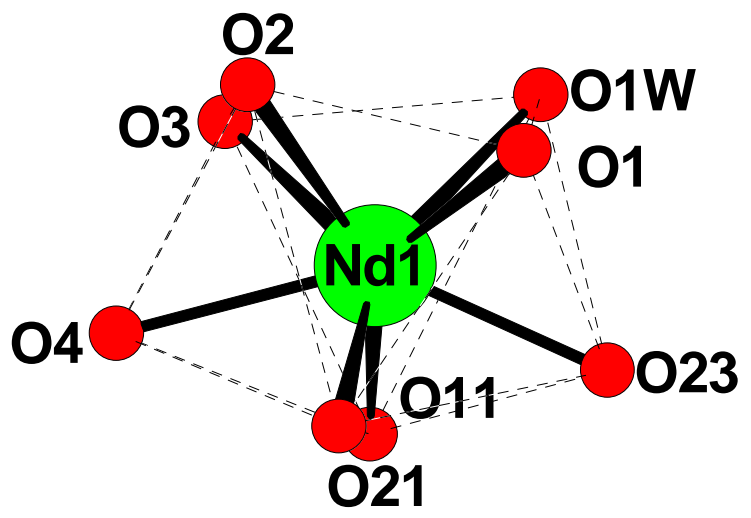

(b)

Figure S1. Coordination Geometries around the La(III) ion in $\mathbf{1}$ (a) and $\mathrm{Nd}(\mathrm{III})$ ion in $\mathbf{2}$ (b). 